\title{
Hypothalamic effects of neonatal diet: reversible and only partially leptin dependent
}

\author{
Luba Sominsky, Ilvana Ziko, Thai-Xinh Nguyen, Julie Quach and Sarah J Spencer
}

School of Health and Biomedical Sciences, RMIT University, Melbourne, Victoria, Australia

Correspondence should be addressed to L Sominsky

Email

Luba.Sominsky@rmit.edu.au

\begin{abstract}
Early life diet influences metabolic programming, increasing the risk for long-lasting metabolic ill health. Neonatally overfed rats have an early increase in leptin that is maintained long term and is associated with a corresponding elevation in body weight. However, the immediate and long-term effects of neonatal overfeeding on hypothalamic anorexigenic pro-opiomelanocortin (POMC) and orexigenic agoutirelated peptide (AgRP)/neuropeptide Y (NPY) circuitry, and if these are directly mediated by leptin, have not yet been examined. Here, we examined the effects of neonatal overfeeding on leptin-mediated development of hypothalamic POMC and AgRP/NPY neurons and whether these effects can be normalised by neonatal leptin antagonism in male Wistar rats. Neonatal overfeeding led to an acute (neonatal) resistance of hypothalamic neurons to exogenous leptin, but this leptin resistance was resolved by adulthood. While there were no effects of neonatal overfeeding on POMC immunoreactivity in neonates or adults, the neonatal overfeeding-induced early increase in arcuate nucleus (ARC) AgRP/NPY fibres was reversed by adulthood so that neonatally overfed adults had reduced NPY immunoreactivity in the ARC compared with controls, with no further differences in AgRP immunoreactivity. Short-term neonatal leptin antagonism did not reverse the excess body weight or hyperleptinaemia in the neonatally overfed, suggesting factors other than leptin may also contribute to the phenotype. Our findings show that changes in the availability of leptin during early life period influence the development of hypothalamic connectivity short term, but this is partly resolved by adulthood indicating an adaptation to the metabolic malprogramming effects of neonatal overfeeding.
\end{abstract}
Key Words
- agouti-related peptide
- developmental programming
- neuropeptide $Y$
- pro-opiomelanocortin
- obesity

Journal of Endocrinology (2017) 234, 41-56

\section{Introduction}

Overfeeding during development has important effects on long-term body weight regulation, potentially leading to sustained obesity in adulthood. Children born to obese mothers or children who rapidly gain weight after birth are at higher risk of lifelong obesity and have an increased susceptibility to obesity-related comorbidities than those born to healthy-weight mothers and those who gain weight more slowly (Whitaker 2004, Boney et al. 2005). Similarly, rats raised in a postnatal environment of overnutrition - in small litters where they are able to consume more milk - become overweight early in life, and this overweight phenotype lasts into adulthood despite a normal diet after weaning (McCance 1962, Spencer \& Tilbrook 2009, Clarke et al. 2012, Stefanidis \& Spencer 
2012). In rodents, the development of the central nervous system (CNS) pathways regulating satiety and energy metabolism occurs after birth (Bouret \& Simerly 2007), and recent evidence suggests that exposure to over- or undernutrition at this critical time may specifically alter the development of these satiety pathways, permanently affecting body weight regulation (Bouret 2009).

One of the major hormonal factors that acts centrally to regulate energy balance and satiety is leptin. In mature healthy individuals, leptin, released by adipocytes, acts as a satiety signal. Within the arcuate nucleus (ARC), leptin activates the anorexigenic pro-opiomelanocortin (POMC) and cocaine- and amphetamine-regulated transcript (CART) neurons. Simultaneously, leptin inhibits the orexigenic neuropeptide Y (NPY) and agouti-related peptide (AgRP) neurons, thus suppressing feeding (Cowley et al. 2001). In obesity, excess adiposity and hence chronically elevated levels of leptin may reduce the sensitivity of leptin receptors, particularly in the ARC, resulting in a resistance to the anorexigenic actions of leptin and further contributing to the maintenance of obesity (Myers et al. 2008). During the early neonatal period when optimal nutrition is required to support an organism's growth, leptin has an additional role, that of stimulating the development of satiety-signalling projections from the ARC to other hypothalamic nuclei (Bouret et al. 2004b, Bouret \& Simerly 2007). Maturation of the hypothalamic satiety-signalling pathways coincides with a surge in circulating leptin levels, occurring between postnatal days (P) 4 and 16 in mice (Ahima et al. 1998, Ahima \& Hileman 2000) and P4-P14 in rats, peaking at P10 (Delahaye et al. 2008, Cottrell et al. 2009). Pharmacological or genetic disruptions to this naturally occurring leptin surge can lead to inappropriate establishment of hypothalamic connectivity, and permanent deficits in satiety signalling, feeding and metabolism. These deficits can be rescued by restoring normal neonatal leptin (Bouret et al. 2004a,b).

In neonatal rodents, one of the major sources of leptin is the maternal milk (Oliver et al. 2002). Therefore, pups raised in small litters, where their access to milk is increased, receive greater and premature exposure to leptin. We, and others, have demonstrated that pups raised in small litters have as much as a sevenfold increase in circulating leptin levels as neonates, compared to their counterparts raised in control litters (Schmidt et al. 2001, Stefanidis \& Spencer 2012). This hyperleptinaemia is associated with a permanent impairment in body weight regulation, as well as reduced responsiveness of ARC neurons to leptin in slice preparations, indicative of acquired leptin resistance (Davidowa \& Plagemann 2000). Plagemann's group has also demonstrated that neonatal overfeeding results in hypermethylation of the main anorexigenic neuropeptide, POMC, within the hypothalamus (Plagemann et al. 2009). This altered methylation pattern may at least partially mediate the long-term programming of obesity in the environment of early overnutrition. No changes in the methylation status or in the hypothalamic content of the orexigenic NPY have yet been observed (Plagemann et al. 2009). However, neonatal overfeeding induced an increase in NPY and AgRP gene expression in at least one study (Lopez et al. 2005), and it also suppresses the responsiveness of the orexigenic NPY gene to ghrelin (Collden et al. 2015), indicating that the NPY system may be similarly vulnerable to the effects of neonatal overfeeding. Despite these suggestions, it is currently unknown if changes in AgRP/NPY gene expression in the hypothalamus are translated into alterations in AgRP/NPY protein within the ARC and other regions of the hypothalamus, if these changes account for hypothalamic leptin resistance and if these effects of neonatal overfeeding persist throughout life. It is also currently unclear if the developmental mal-programming of this hypothalamic connectivity by neonatal overfeeding is directly mediated by neonatal hyperleptinaemia, since additional factors may contribute to this developmental programming. For instance, we and others have demonstrated that neonatal overfeeding stimulates acute changes in circulating ghrelin and acute hypothalamic hyperresponsiveness to ghrelin, suggesting ghrelin may also contribute to metabolic outcomes in the neonatally overfed (Collden et al. 2015, Sominsky et al. 2016a). In this study, we therefore examined the immediate and long-term effects of neonatal overfeeding on the establishment of the hypothalamic POMC neurons and AgRP/NPY fibres as well as the sensitivity of the hypothalamus to leptin. To directly assess leptin's involvement, we also tested if suppressing the neonatal effects of hyperleptinaemia with a leptin antagonist would re-establish normal hypothalamic circuitry despite neonatal overfeeding.

\section{Materials and methods}

\section{Animals}

We obtained all our timed pregnant Wistar rats from the Animal Resources Centre, WA, Australia. On arrival at the RMIT University Animal Facility, we housed them at

Published by Bioscientifica Ltd. 
$22^{\circ} \mathrm{C}$ on a $12 \mathrm{~h}$ light/darkness cycle $(07: 00-19: 00 \mathrm{~h})$ and provided them with standard pelleted rat chow and water ad libitum. Chow composition was as described in Kenny and colleagues (Kenny et al. 2014). We conducted all procedures in accordance with the National Health and Medical Research Council Australia Code of Practice for the Care of Experimental Animals and RMIT University Animal Ethics Committee approval.

\section{Litter size manipulation}

On the day of birth (P0), we removed all pups from their dams and randomly fostered them to new dams in litters of 12 (control litter; CL) or four (small litter, SL, neonatal overfeeding) as we have previously described (Spencer \& Tilbrook 2009, Smith \& Spencer 2012, Stefanidis \& Spencer 2012). Dams did not receive any of their own pups, and each new litter was made up of $50 \%$ males and 50\% females. Excess pups were culled. This litter size manipulation results in SL pups being significantly heavier by P7 and heavier throughout life (Spencer \& Tilbrook 2009, Smith \& Spencer 2012, Stefanidis \& Spencer 2012).

We used the offspring in experimentation either as neonates (P7, P12 or P14) or allowed them to grow into adulthood, approximately P70. In this latter case, we separated the pups into same-sex littermate pairs upon weaning at P21 and left them undisturbed until experimentation, except for the usual animal husbandry. We used only males in these experiments, keeping the females for use in other studies. We derived all experimental groups from three or more litters per group, using a maximum of two pups from the same litter for an experimental treatment. We ran all experiments in the beginning of the light phase of the $12 \mathrm{~h}$ light/darkness cycle, except where stated.

\section{Effects of neonatal overfeeding on neonatal circulating leptin}

On P7 or P14, we deeply anaesthetised a cohort of neonatally overfed and control rats with Lethabarb $(150 \mathrm{mg} / \mathrm{kg}$ pentobarbitone sodium, i.p.), decapitated them and collected trunk blood for later assessment of plasma leptin. Whole blood was collected on ice and quickly centrifuged to separate the plasma. Plasma samples were stored at $-20^{\circ} \mathrm{C}$ until use.

To determine circulating leptin concentrations, we performed a magnetic beads-based Bio-Plex Pro Diabetes Leptin (Bio-Rad) assay, using a Bio-Plex MAGPIX instrument according to the manufacturer's instructions. We analysed the data using Bio-Plex Manager Software 6.1 (Bio-Rad Laboratories). Intra-assay variability was 4\% coefficient of variance (CV), inter-assay variability was 3\% $\mathrm{CV}$, and lower limit of detection was $5 \mathrm{pg} / \mathrm{mL}$. Samples were assayed in duplicate and were all processed in the same assay.

\section{RNA isolation, reverse transcription and quantitative real-time PCR}

To assess whether neonatal overfeeding alters the expression of the leptin receptor, we also took brains from the animals described above and conducted qRT-PCR. Thus, immediately after trunk blood collection, we dissected the brains into the right ARC and left hypothalamus not containing ARC. These samples were immediately snapfrozen in liquid nitrogen and stored at $-20^{\circ} \mathrm{C}$ until use. We isolated total RNA using QIAzol reagents and RNeasy Mini Kits (Qiagen). We determined RNA concentrations using a spectrophotometer, NanoDrop 2000/2000c (Thermo Fisher Scientific). $1 \mu \mathrm{g}$ RNA was transcribed to cDNA using an iScript cDNA synthesis kit (Bio-Rad Laboratories), according to the manufacturer's instructions.

We performed qRT-PCR using Taqman Gene Expression Assays (Applied Biosystems) on a Rotor-Gene $\mathrm{Q}$ instrument (Qiagen $\mathrm{GmbH}$ ). We compared a relative quantitative measure of expression of the target gene mRNA (Lepr: NCBI Reference Sequence=NM_012596; TaqMan Assay ID = Rn01433205_ml; Product size =94) with an endogenous control 18s (18s: X03205.1; 4319413E; 187) and analysed the data using the equation $2^{-\Delta \Delta C(t)}$, where $C(t)$ is the threshold cycle at which fluorescence is first detected significantly above background (Schmittgen \& Livak 2008). Minus-reverse transcriptase (-RT) controls omitting the reverse transcriptase reaction and No Template Controls (NTC) with no primer in the reaction were run to determine no genomic DNA or DNA contamination was present. Data are presented as a fold increase relative to P7 CL (neonates) or adult CL (adults).

\section{Weights and neuronal activation in response to leptin}

To assess if neonatal overfeeding was likely to influence metabolic responses to leptin, we assessed weight changes (as a neonatal proxy for food intake) and neuronal activation in response to $3 \mathrm{mg} / \mathrm{kg}$ i.p. recombinant rat leptin (PeproTech, Rocky Hill, NJ, USA) or saline at P12 in neonatally overfed and control rats. We chose this 
dose based on those used in previously published studies (Proulx et al. 2002, Frontini et al. 2008). Pups were weighed immediately before and $45 \mathrm{~min}$ after injection. At $45 \mathrm{~min}$ we deeply anaesthetised them with Lethabarb and perfused them transcardially with phosphate-buffered saline (PBS: $4^{\circ} \mathrm{C}, \mathrm{pH} 7.4$ ), followed by $4 \%$ paraformaldehyde (PFA) in $\mathrm{PBS}\left(4^{\circ} \mathrm{C}, \mathrm{pH} 7.4\right)$ for immunohistochemical analysis of phosphorylated signal transducer and activator of transcription 3 (pSTAT3) as a marker of leptin-induced neuronal activation. Brains were removed and post-fixed for $24 \mathrm{~h}$ in the same fixative before placing them in $20 \%$ sucrose in $\mathrm{PBS}\left(4^{\circ} \mathrm{C}\right)$. We then cut the forebrains into $40 \mu \mathrm{m}$ (neonates) or $30 \mu \mathrm{m}$ (adults) coronal sections using a cryostat. Sections were cut in a one in five series and were stored in $0.1 \mathrm{M} \mathrm{PB}$ containing $0.02 \%$ sodium azide at $4^{\circ} \mathrm{C}$ until use. All experiments took place between 09:00 and 13:00 h to limit potential effects of circadian rhythms on any parameters measured.

\section{Immunohistochemistry}

Sections through the hypothalamus were immunolabelled for PSTAT3 (CL and SL, saline or leptin-treated rats), POMC (CL and SL rats), AgRP (CL and SL rats) or NPY (CL and SL rats). Randomly selected animals from each treatment group were processed at the same time in batches. Briefly, we incubated a single one in five series of sections from each animal in primary antibody (pSTAT3: 1:5000; rabbit; overnight; $4^{\circ} \mathrm{C}$; Abcam. POMC: 1:5000; rabbit; overnight; $4^{\circ} \mathrm{C}$; Phoenix Pharmaceuticals, Burlingame, CA, USA. AgRP: 1:500; goat; $42 \mathrm{~h}$; room temperature; Neuromics Inc., MN, USA. NPY: 1:1000; rabbit; overnight; $4^{\circ} \mathrm{C}$; Sigma-Aldrich), followed by secondary antibody (pSTAT3: 1.5 h; 1:500; biotinylated anti-rabbit; Vector Laboratories, Burlingame, CA, USA. POMC: $1 \mathrm{~h} ; 1: 500$ in neonatal and 1:200 in adult brains; Alexa-fluor 488 goat anti-rabbit; Thermo Scientific. AgRP: 12 h 1:200 Alexa-fluor 594 rabbit anti-goat; Thermo Scientific. NPY: 2h; 1:500; Alexa-fluor 488 goat anti-rabbit; Thermo Scientific). pSTAT3 sections were then incubated with avidin-biotin horseradish peroxidase (HRP) complex (ABC; 45 min; Vector Elite kit; Vector), followed by diaminobenzidine (DAB) intensified with nickel (black staining) to visualize the HRP activity. We stopped the reaction when the contrast between specific cellular and non-specific background labelling was optimal. We mounted the sections on polylysinecoated slides, air-dried them, dehydrated them in a series of alcohols, cleared them in histolene and coverslipped them. POMC, AgRP and NPY were counterstained with
DAPI for $15 \mathrm{~min}$ and mounted on slides with DAKO antifading solution.

The antibodies used in our study have been previously validated by the manufacturers and other researchers using pre-absorption experiments, testing of the pre-immune sera and/or western blotting to confirm the expected size of the proteins. Thus, the pSTAT3 antibody has been validated by the manufacturer by western blotting, using untreated HeLa cell lysate (negative control) and HeLa cell lysate treated with interferon $\alpha$ (positive control), producing a detectable band at the predicted molecular weight $(88 \mathrm{kDa})$, and has been used by others (Desai et al. 2007, McGuckin et al. 2013, Mao et al. 2016).

The specificity of POMC antibody, H-029-30, Phoenix Pharmaceuticals, has been confirmed by Wittmann and colleagues (Wittmann et al. 2013), by dual immunofluorescence of rat and mouse hypothalamic sections using a sheep $\alpha$-Melanocyte-stimulating hormone antiserum ( $\alpha-\mathrm{MSH})$. As expected, based on the well-known distribution of POMC neurons (Elias et al. 1999), the $\alpha$-MSH antiserum labelled fewer cell bodies compared to the POMC antiserum, while all $\alpha$-MSH immunoreactive cells have been labelled by the POMC antiserum. In addition, western blot analysis in mouse pituitary has been performed by Berman and colleagues (Berman et al. 2001), showing a predominant and predicted band at $23 \mathrm{kDa}$. This antibody has also been used by several other researchers for immunohistochemical localisation of POMC in feeding, stress or nociception-related studies (for example: Gotoh et al. 2006, Reyes et al. 2006, Evans et al. 2007, DeBoer et al. 2009, Cheng et al. 2011, Singru et al. 2012, Tavares et al. 2013, Zhan et al. 2013, Pandit et al. 2016).

The AgRP antibody, GT15023, Neuromics, has been validated by the manufacturer using antiserum on fixed tissue, and has been used by other researchers in experimental settings that included specific targeting of AgRP neurons by food restriction, administration of ghrelin and/or genetic modification (Cheunsuang \& Morris 2005, Kobelt et al. 2008, Cao et al. 2011, Li et al. 2012, Betley et al. 2015, Garfield et al. 2015, Kim et al. 2016, Shibata et al. 2016).

The NPY antibody, N9528, Sigma-Aldrich, has been validated by the manufacturer. Anti-NPY has been shown to react with NPY conjugated to BSA in a dot blot. The antiserum shows cross-reactivity with NPY and NPY fragments, but not with substance $\mathrm{P}$, neurokinin $\mathrm{A}$, neurokinin $\mathrm{B}$, vasoactive intestinal peptide, calcitonin gene-related peptide, calcitonin and somatostatin

Published by Bioscientifica Ltd 
conjugated to BSA or to BSA itself. Anti-NPY has also been shown to react with NPY-containing neurons in frozen rat brain sections following $4 \%$ paraformaldehyde perfusion fixation. This antibody has been used in several studies looking at the effects of diet manipulation or treatment with feeding-regulatory peptides such as orexins, leptin or ghrelin on NPY immunohistochemical expression (for example: Cheunsuang \& Morris 2005, Kobelt et al. 2008, Garcia et al. 2010, 2011, Li et al. 2012, Konieczna et al. 2013, Pekala et al. 2011).

Specificity of the antibodies was further supported by incubating ARC and/or PVN sections, where applicable, without a primary or without a secondary antibody in the neonatal and adult brain. Positive labelling was confirmed in the specific regions of interest.

Hypothalamic sections were assessed by an experimenter blinded to treatment groups. For the numbers of cells positive for pSTAT3, we counted total cell numbers in the ARC and ventromedial hypothalamus (VMH). We analysed three sections (left and right) $120 \mu \mathrm{m}$ apart between 2.76 and $3.48 \mathrm{~mm}$ caudal to bregma per animal. We saw no differences between the rostrocaudal levels for any of the regions, so we took the summed counts of the three sections as our sampled result.

For POMC, AgRP and NPY, photomicrograph images were taken on an upright confocal laser-scanning microscope (Nikon Eclipse 90i) using $561 \mathrm{~nm}$ and $488 \mathrm{~nm}$ lasers with 605/75 and 515/30 filter sets, respectively, with DAPI being detected under the $408 \mathrm{~nm}$ laser. ARC and PVN images were viewed under the $20 \times$ objective lens using the galvano scanner and a scan size of $512 \times 512$ pixels. NIS Elements Advanced Research Software (Nikon) was used to estimate fluorescence signal intensity within the ARC and PVN. Laser and detector levels were optimised on sections not included in the analysis and kept constant throughout the imaging. All slides were blinded from the experimenter.

POMC-positive cells in the ARC were manually counted using Image J (National Institutes of Health) in four brain sections between 2.76 and $3.48 \mathrm{~mm}$ caudal to bregma per animal. Summed counts of the four sections were taken as our sampled result.

AgRP and NPY cell fibres were detected by the thresholding method. Background was subtracted, and threshold lower and upper limits were determined based on brain sections from the control group of animals. These settings were kept constant throughout the analysis. In our experiments, perikaryon AgRP and NPY labelling were observed in neonatal ARC only, and neither in the PVN, nor in adult ARC or PVN. In order to exclude cell body labelling in the neonatal ARC analysis, we used NIS Elements Advanced Research Software to define threshold layers for both channels (DAPI and Alexa 594 for AgRP labelling and DAPI and Alexa 488 for NPY labelling) based on the immunofluorescence labelling intensity. The thresholds for each of the channels were defined separately, and the software subtracted DAPI layer from either AgRP or NPY layer, providing a new layer with the cell bodies excluded. This layer was then analysed. Based on our analysis, the subtracted nuclear staining is optimal, rendering cytoplasmic staining negligible. The area of intensity within a region of interest was quantified in a sub-region of interest (as indicated in Fig. 2), identified according to the Paxinos and Watson Rat Brain Atlas (Paxinos \& Watson 2009), and analysed in four sections $120 \mu \mathrm{m}$ apart between 2.76 and $3.48 \mathrm{~mm}$ caudal to bregma per animal.

\section{Effects of neonatal overfeeding on the adult leptin system}

As our results showed significant effects of neonatal overfeeding on the neonatal leptin system, we assessed a further cohort of animals in adulthood to determine if effects were maintained past the neonatal period. We allowed a cohort of CL and SL rats to grow to $\sim$ P70 and assessed leptin receptor expression, weight and hypothalamic responses to leptin, POMC-, AgRP- and NPY-immunoreactivity as described above. For food intake measurements, we singly housed CL and SL adult rats and injected $3 \mathrm{mg} / \mathrm{kg}$ i.p. leptin (or saline) immediately prior to lights off (i.e. between 18:30 and 18:50). Each rat was given access to a pre-weighed amount of pelleted rat chow. We monitored food intake and body weight at 12 and $24 \mathrm{~h}$ post injection. After 7 days recovery, we assessed neuronal activation in these rats in response to $1 \mathrm{mg} / \mathrm{kg}$ i.p. leptin, having determined in pilot experiments that this dose is sufficient to activate the ARC and $\mathrm{VMH}$; and based on Sachot and colleagues (Sachot et al. 2007). We assessed plasma leptin levels using a standard leptin ELISA (Millipore) following the manufacturer's instructions. Intra-assay variability was $1.9-2.5 \% \mathrm{CV}$, inter-assay variability, $3.0-3.9 \% \mathrm{CV}$ and lower limit of detection, $0.04 \mathrm{ng} / \mathrm{mL}$. Samples were assayed in duplicate and were all processed in the same assay.

\section{Neonatal leptin antagonist treatment}

To test if preventing the effects of an exacerbated and premature surge in SL would normalise long-term

Published by Bioscientifica Ltd. 
A
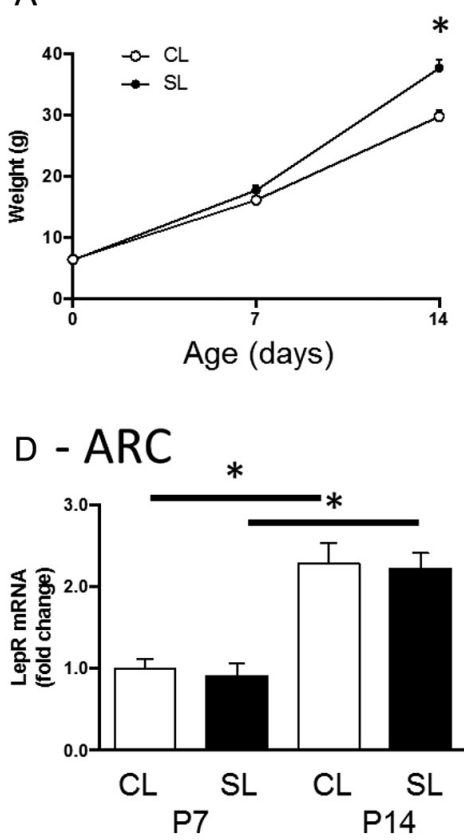

B

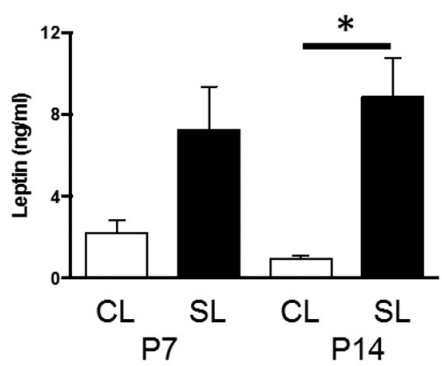

E - VMH

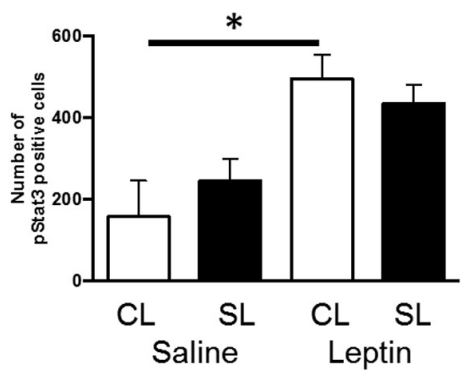

c - hypothalamus

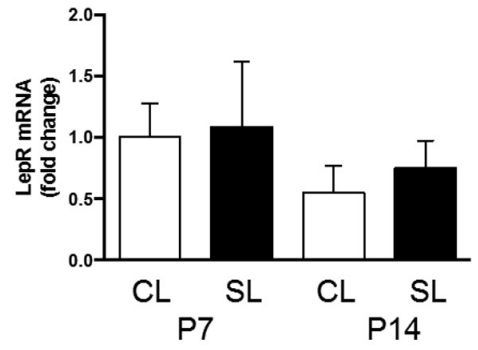

$F-A R C$

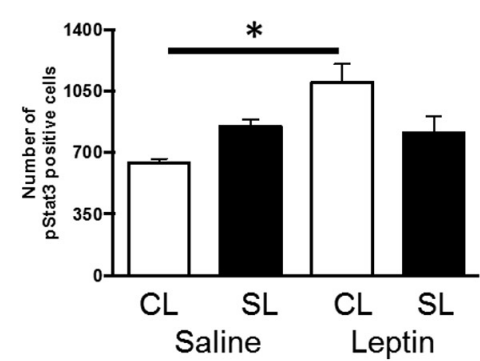

G - P12 pSTAT3 ARC

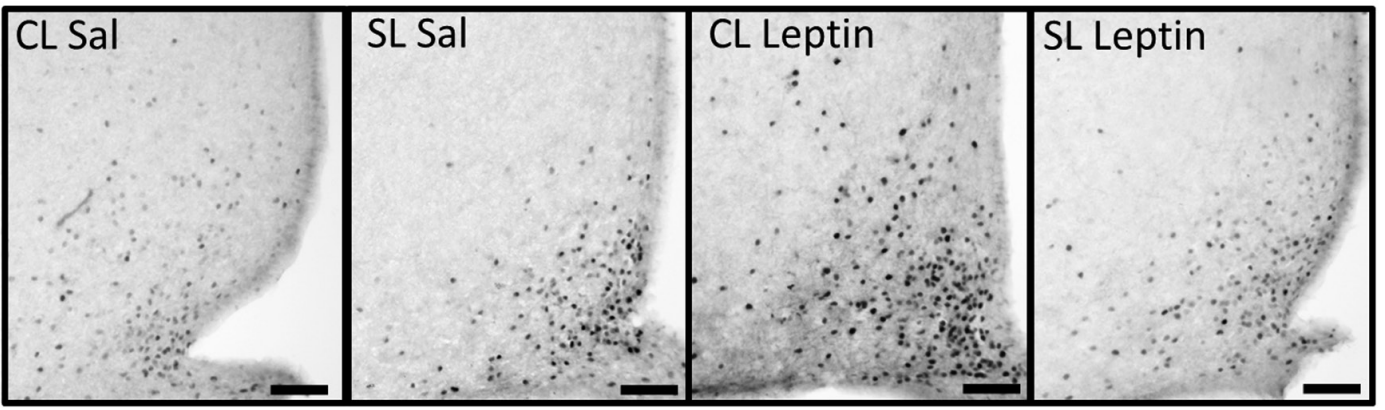

Figure 1

Effects of neonatal overfeeding on the neonatal leptin system. (A) Pre-weaning body weights of control (CL) and neonatally overfed (SL) rats. (B) Plasma leptin concentrations at postnatal day (P)7 and 14. (C) Hypothalamic; (D) arcuate nucleus (ARC) leptin receptor expression. (E) Neuronal activation in response to leptin injection at P12; numbers of phosphorylated signal transducer and activator of transcription (pSTAT3)-positive cells in the ventromedial hypothalamus (VMH). (F) Numbers of pSTAT3-positive cells in the ARC. (G) Representative photomicrographs showing leptin-induced pSTAT3-positive cells in the ARC of CL and SL rats. Data are mean + S.E.M. ${ }^{*} P<0.05$. Scale bars $=200 \mu \mathrm{m}$.

disruption to leptin signalling, we administered rat super-active leptin antagonist (SRLA; SLAN-4; Protein Laboratories Rehovot Ltd., Rehovot, Israel) or saline at $5 \mathrm{mg} / \mathrm{kg}$ i.p. to a cohort of CL and SL rat pups daily from P4 to P7. Leptin antagonist has been developed by substituting a leptin residue D23 with a nonnegatively charged amino acid. This results in increased affinity of leptin for its soluble receptor. Therefore, this antagonist blocks the leptin action by competing with endogenous leptin for binding to the leptin receptor (Shpilman et al. 2011). The dosage and timing were derived from previous publications (Mela et al. 2015,
2016) where the same dose and similar timing were found to be effective without leading to the negative effects seen with higher doses and longer treatment protocols. We have also recently shown that this dose and timing successfully rescue neonatal overfeedinginduced follicular attrition in females (Sominsky et al. 2016b). After treatment, the rats were left undisturbed until adulthood (P56), apart from routine monitoring at which time they were deeply anesthetised with an overdose of Lethabarb ( $150 \mathrm{mg} / \mathrm{kg}$ i.p.) and perfused transcardially with $4 \%$ PFA as described above. We then assessed weights, circulating leptin levels, the number 

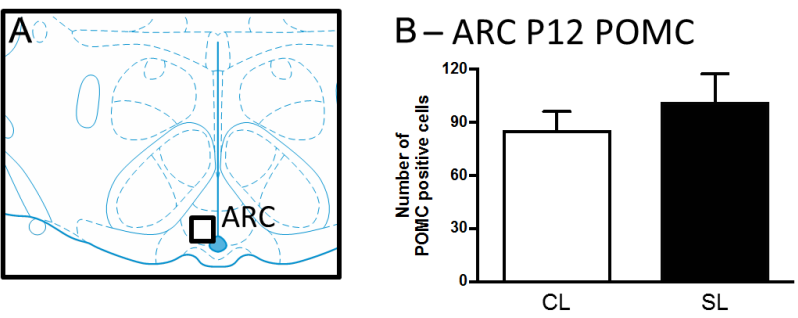

F- ARC P12 AgRP

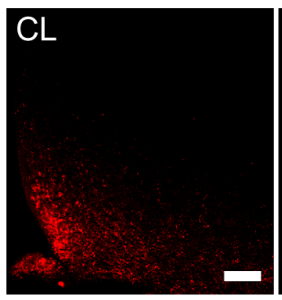

C - ARC P12 AGRP

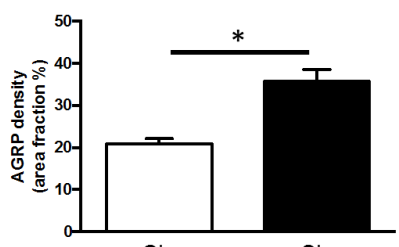

SL

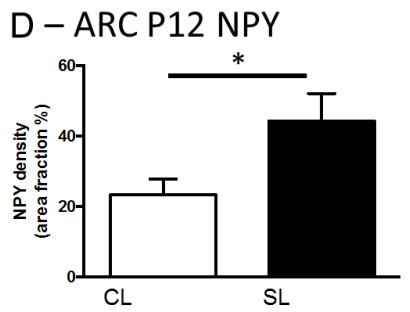

E-ARC P12 POMC
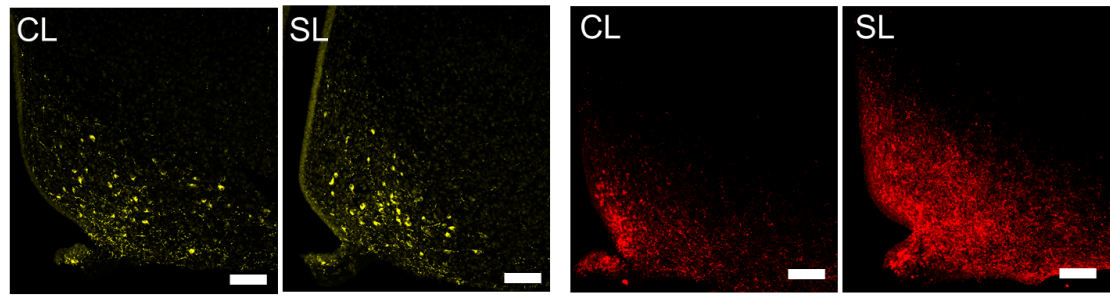

G - ARC P12 NPY
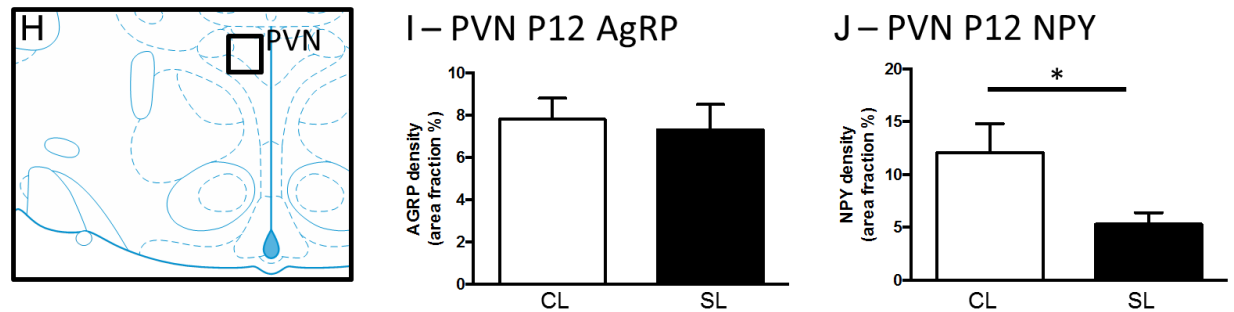

\section{K-PVN P12 AgRP}

\section{L - PVN P12 NPY}
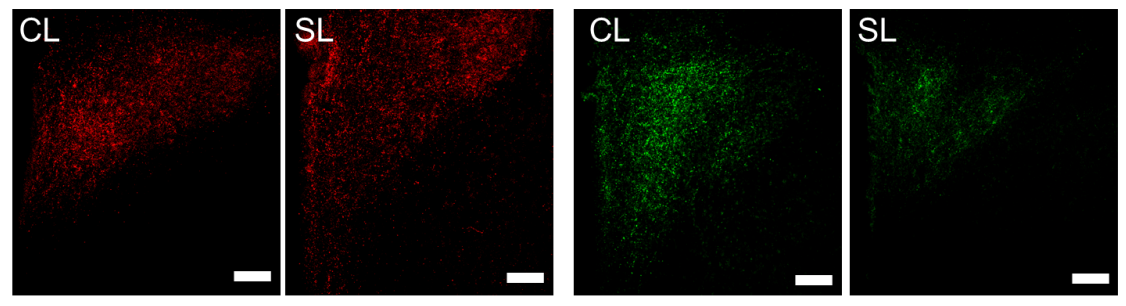

Figure 2

Effects of neonatal overfeeding on neonatal hypothalamic NPY density. (A, H) Schematic diagram adapted from Paxinos and Watson (2009) illustrating the region of interest sampled for pro-opiomelanocortin (POMC), agouti-related peptide (AgRP) and neuropeptide $Y$ (NPY) labelling in the arcuate nucleus (ARC) and the paraventricular nucleus of the hypothalamus (PVN) in control (CL) and neonatally overfed (SL) rats. (B) POMC labelling in the ARC. (C) AgRP labelling in the ARC. (D) NPY labelling in the ARC. (E) Representative photomicrographs showing POMC labelling in the ARC in CL and SL rats at P12. (F) Representative photomicrographs showing AgRP labelling in the ARC in CL and SL rats at P12. (G) Representative photomicrographs showing NPY labelling in the ARC in CL and SL rats at P12. (I) AgRP labelling in the PVN. (J) NPY labelling in the PVN. (K) Representative photomicrographs showing AgRP in the PVN in CL and SL rats at P12. (L) Representative photomicrographs showing NPY in the PVN in CL and SL rats at P12. Data are mean+s.E.M. ${ }^{*} P<0.05$. Scale bars $=100 \mu \mathrm{m}$. A full colour version of this figure is available at $\mathrm{http}: / / \mathrm{dx}$. doi.org/10.1530/JOE-16-0631.

of POMC-positive cells and density of AgRP and NPY fibres as described.

\section{Statistical analysis}

We analysed neonatal and adult changes separately. For neonates we compared weights, leptin, leptin receptor expression, weight and hypothalamic responses to leptin, using multi-factorial analyses of variance (ANOVAs) with neonatal nutritional environment (CL/SL) and age (P7/14) as between factors. For neonatal pSTAT3, POMC-, AgRP- and NPY-immunoreactivity, and for the adults, we used Student's unpaired t-tests or two-way ANOVAs, also including treatment factors where appropriate (saline/ leptin or saline/SRLA). Where significant interactions were found, we then performed Tukey post hoc tests. Data are presented as the mean+S.E.M. Statistical significance was assumed when $P \leq 0.05$.
๑ 2017 Society for Endocrinology Printed in Great Britain 


\section{Results}

\section{Neonatal overfeeding leads to acute changes in the leptin system}

As we have previously seen (Spencer \& Tilbrook 2009, Smith \& Spencer 2012, Stefanidis \& Spencer 2012), neonatal overfeeding leads to accelerated growth in early life so those raised in small litters (neonatally overfed) were significantly heavier than controls at P14 $\left(F_{(2,28)}=20.75, \quad P<0.001 ; n=8\right.$ per group; Fig. $\left.1 \mathrm{~A}\right)$. We have also previously reported circulating leptin levels are markedly higher in neonatally overfed rats than in controls at P14 (Stefanidis \& Spencer 2012) and our findings here reflect this. Thus, there is a significant age by litter size interaction and significant differences between the controls and neonatally overfed at P14 $\left(F_{(1,22)}=16.18\right.$, $P<0.001 ; n=6-8$; Fig. 1B). Expression of leptin receptor mRNA in the hypothalamus, and ARC was not affected by neonatal overfeeding (Fig. 1C and D), but it was significantly elevated at P14 compared with P7 in the ARC in both groups (significant effect of age: $F_{(1,23)}=51.37$, $P<0.001 ; n=6-8$; Fig. 1D).

To test if neonatal overfeeding alters the neonates' ability to respond to a leptin signal, we gave them a single injection of leptin at P12 and examined weight changes (as a neonatal proxy for food intake) and hypothalamic pSTAT3 expression. There were no differences in $45 \mathrm{~min}$ weight gain between any of the groups (data not shown). However, there was a significant effect of neonatal overfeeding on the activation of the $\mathrm{VMH}$ in response to leptin with leptin stimulating VMH activation in control but not in neonatally overfed neonatal rats (significant effect of leptin: $F_{(1,15)}=18.82, P=0.001 ; n=3-6$; Fig. 1E). Neonatal overfeeding also led to leptin resistance in the ARC, with leptin stimulating ARC activation in the control but not in the neonatally overfed (significant interaction: $F_{(1,15)}=8.54, P=0.011 ; n=3-6$; Fig. 1 F and G).

\section{Neonatal overfeeding does not affect POMC immunoreactivity, but acutely disrupts hypothalamic AgRP and NPY}

To determine if the elevation in neonatal leptin associated with neonatal overfeeding leads to a disruption in hypothalamic POMC, AgRP or NPY, as has been seen with other models of neonatal leptin disruption (Bouret et al. 2004b, Bouret \& Simerly 2006, Plagemann et al. 2009), we examined changes in POMC-positive cells in the ARC, as well as AgRP- and NPY-immunoreactive fibres in the ARC (Fig. 2A) and the PVN (Fig. 2F). There were no differences in the number of POMC-positive cells (Fig. 2B and E). Neonatal overfeeding, however, significantly increased AgRP fibre density in the ARC relative to controls $\left(t_{(9)}=5.18, P=0.001 ; n=5-6\right.$ per group Fig. $2 \mathrm{C}$ and F). There was no effect of neonatal overfeeding on the density of AgRP fibres at P12 in the PVN (Fig. 2I and K). Neonatal overfeeding also affected NPY immunoreactivity in both regions. Thus, at P12, NPY labelling was robust and dense with a dense network of positively labelled fibres. The neonatally overfed rats had a significantly increased density of NPY fibres in the ARC compared with controls $\left(t_{(10)}=2.33, P=0.042 ; n=6\right.$ per group; Fig. $2 \mathrm{D}$ and $\mathrm{G})$. By contrast, neonatal overfeeding reduced the density of NPY fibres in the PVN compared with controls at P12 $\left(t_{(10)}=2.3, P=0.044 ; n=6\right.$ per group; Fig. $2 \mathrm{~J}$ and L).

\section{Neonatal overfeeding-induced disruption to the leptin system is partially resolved in adulthood}

To assess if the neonatal overfeeding-induced effects on the hypothalamus influences this system long term, we assessed leptin, leptin receptor expression, POMC-, AgRP- and NPY-immunoreactivity, as well as weight and hypothalamic responses to leptin in adult neonatally overfed and control rats. The weight phenotype was maintained into adulthood $\left(t_{(21)}=2.24, P=0.036 ; n=11-12\right.$ per group; Fig. 3A) and as previously reported (Stefanidis $\&$ Spencer 2012), adult rats that were overfed as neonates had more circulating leptin than controls $\left(t_{(14)}=3.34\right.$, $P=0.0049 ; n=6-10$; Fig. 3B). As with the neonates, there were no differences in receptor expression in the hypothalamus (Fig. 3C). There were also no differences in the number of POMC-positive cells in the adult ARC (Fig. 3D and I). Despite differences in circulating leptin in the adults and disruptions in the AgRP/NPY network in the neonatal period, there was no long-term effect of neonatal overfeeding on AgRP labelling in the adult ARC (Fig. 3E and J) or PVN (Fig. 3G and L). In the ARC, NPY was suppressed in SL relative to controls in a profile opposite to that seen in the neonates $\left(t_{(10)}=2.32, P=0.043\right.$; Fig. 3F and $\mathrm{K}$ ). The effect of neonatal overfeeding on PVN NPY density was normalised in the adults (Fig. $3 \mathrm{H}$ and $\mathrm{M}$ ).

If neonatal overfeeding resulted in long-term resistance, we would expect the neonatally overfed rats to be unresponsive to exogenous leptin as adults. Exogenous leptin injection suppressed food intake during the nocturnal phase overall (significant effect of leptin $F_{(1,46)}=3.97, P=0.052$; Fig. 4 A), but there were

Published by Bioscientifica Ltd. 
A

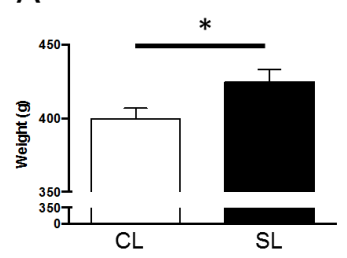

E- ARC AgRP

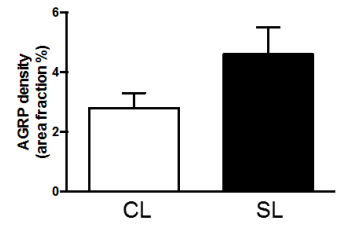

B

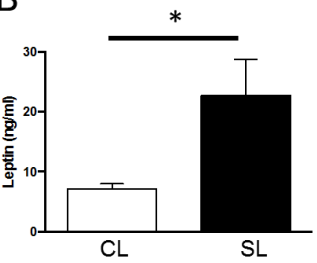

$F-A R C N P Y$

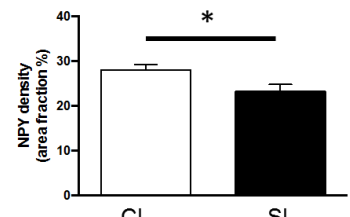

SL
C- hypothalamus

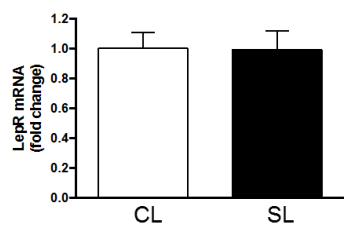

G- PVN AgRP

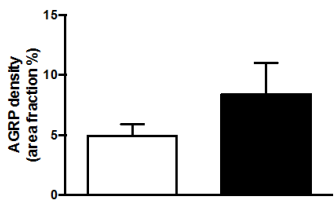

SL

D - ARC POMC

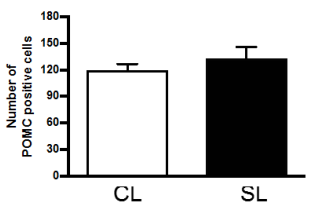

$\mathrm{H}-\mathrm{PVN} N \mathrm{NPY}$

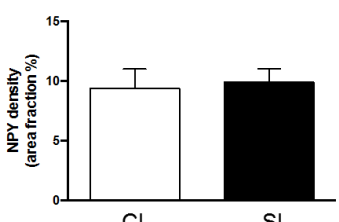

K-ARC NPY

I-ARC POMC

J-ARC AgRP
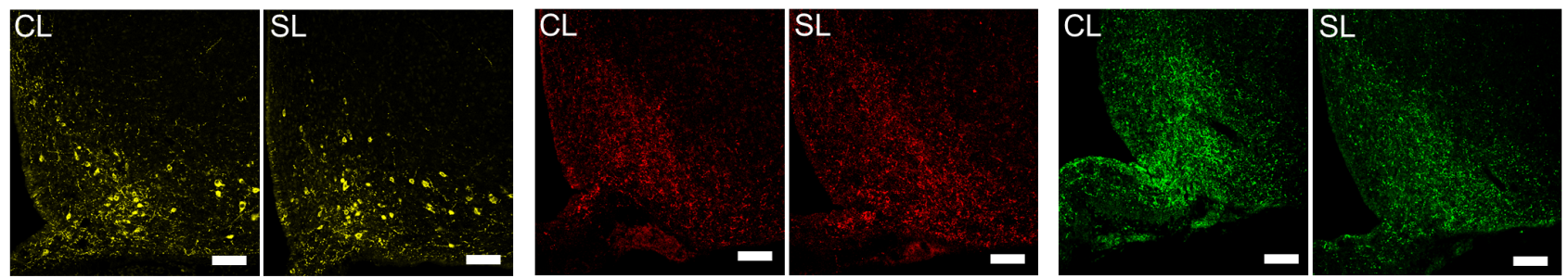

\section{L - PVN AgRP}

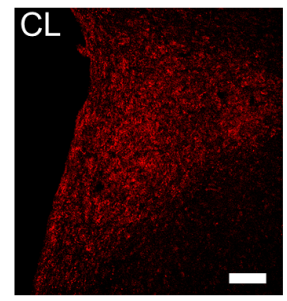

\section{M - PVN NPY}
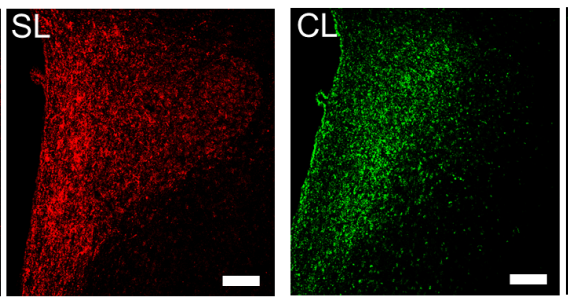

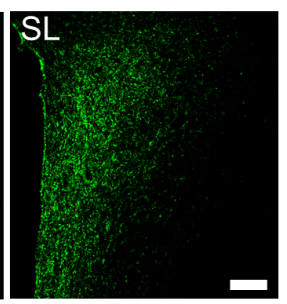

\section{Figure 3}

Effects of neonatal overfeeding on the leptin system long term. (A) Adult (P60) body weights of control (CL) and neonatally overfed (SL) rats. (B) Plasma leptin concentrations. (C) Hypothalamic leptin receptor expression. (D) Pro-opiomelanocortin (POMC) labelling in the arcuate nucleus (ARC).

(E) Agouti-related peptide (AgRP) in the ARC. (F) Neuropeptide Y (NPY) labelling in the ARC. (G) AgRP labelling in the paraventricular nucleus of the hypothalamus (PVN). (H) NPY labelling in the PVN. (I, J, K) Representative photomicrographs showing POMC, AgRP and NPY in the ARC in CL and SL adult rats. (L, M) Representative photomicrographs showing AgRP and NPY in the PVN in CL and SL adult rats. Data are mean + S.E.M. ${ }^{*} P<0.05$. Scale bars $=100 \mu \mathrm{m}$. A full colour version of this figure is available at http://dx.doi.org/10.1530/JOE-16-0631.

no post hoc differences between the groups and no differences in the diurnal food intake (Fig. 4B). We saw a similar pattern with total $24 \mathrm{~h}$ food intake (significant effect of leptin $F_{(1,46)}=4.42, P=0.041$; Fig. 4C). Similarly, exogenous leptin significantly activated neurons in the ARC overall, but there were no differences in the responses between the neonatally overfed and controls (significant effect of leptin: $F_{(1,18)}=4.92, P=0.040$; Fig. 4D and $\mathrm{E})$. There was thus no evidence of hypothalamic leptin resistance in neonatally overfed adults relative to controls.
Neonatal leptin antagonist does not reverse the long-term effects of neonatal overfeeding on weight or circulating leptin

To assess if the effects of neonatal overfeeding on weight, leptin and satiety-signalling pathways are a direct result of neonatal hyperleptinaemia, we next examined if acute leptin antagonist at the onset of the leptin surge could reverse some of the long-term effects of neonatal overfeeding. Suppressing the activity of neonatal leptin did not affect weight gain in the short term, with a main effect of litter size at P21 $\left(F_{(1,18)}=34.50, P<0.001 ; n=5-6\right.$; 
A

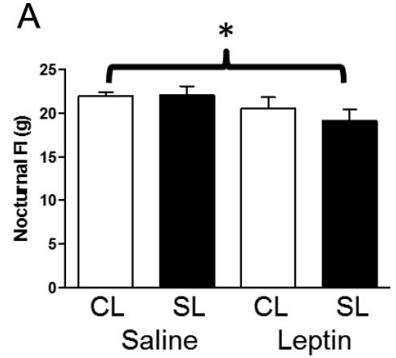

B

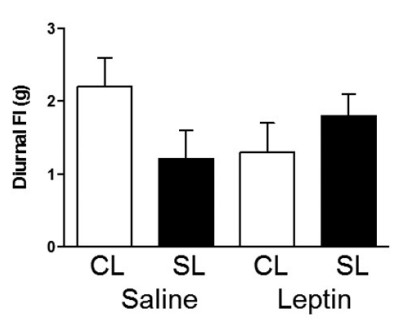

C

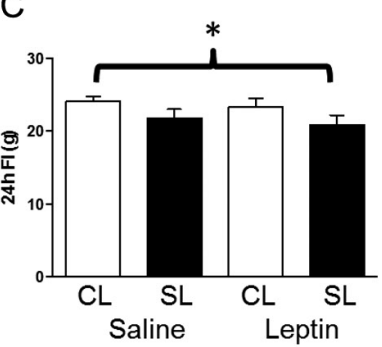

D

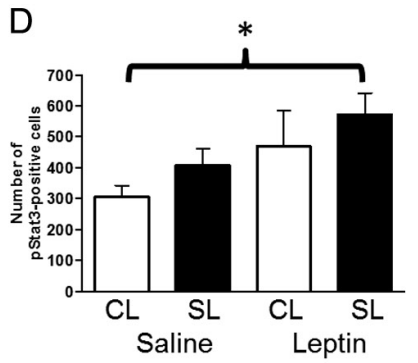

\section{E- adult pSTAT3 ARC}
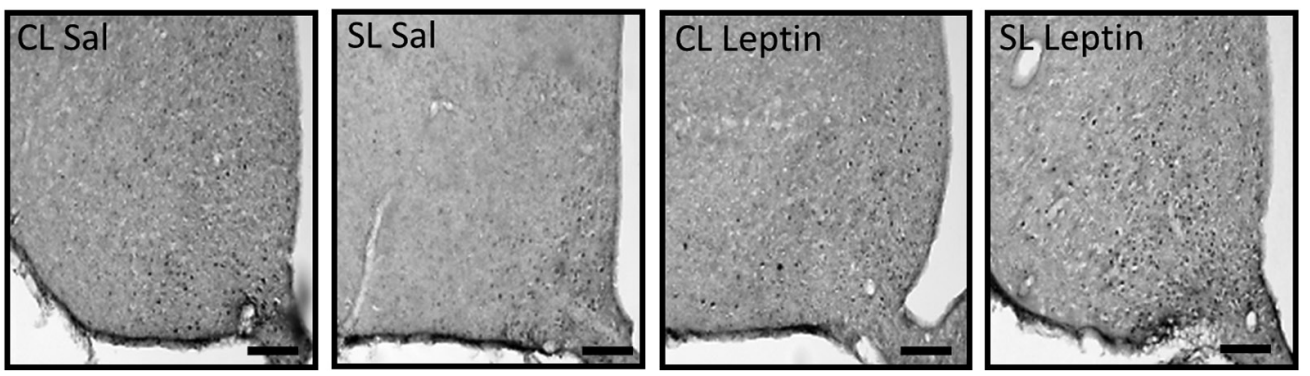

\section{Figure 4}

Long-term effects of neonatal overfeeding on responses to leptin. (A) Nocturnal food intake following exogenous leptin in control (CL) and neonatally overfed (SL) rats. (B) Diurnal food intake. (C) Total (24h) food intake. (D) Neuronal activation in response to leptin injection; numbers of phosphorylated signal transducer and activator of transcription (pSTAT3)-positive cells in the arcuate nucleus (ARC). (E) Representative photomicrographs leptin-induced pSTAT3-positive cells in the ARC in CL and SL adult rats. Data are mean+s.E.M. Parentheses in A, C and D indicate significant main effect of litter size.

${ }^{*} P<0.05$. Scale bars $=100 \mu \mathrm{m}$.

Fig. 5A). It also failed to normalise adult weights (main effect of litter size at P63: $F_{(1,18)}=9.54, P=0.006 ; n=5-6$; Fig. 5B) or circulating leptin (main effect of litter size: $F_{(1,15)}=11.13, P=0.005 ; n=5-6$; Fig. 5C). There was no effect on the number of POMC-positive cells in the ARC (Fig. 5D). The neonatal leptin antagonist significantly reduced adult AgRP labelling in the ARC in control and neonatally overfed animals $\left(F_{(1,19)}=6.82, P=0.017 ; n=5-6\right.$; Fig. 5E), but did not affect NPY immunoreactivity. There was a main effect of litter size on NPY levels in the adult ARC $\left(F_{(1,19)}=5.31, P=0.033 ; n=5-6\right.$; Fig. 5F), but no further post hoc differences between the groups. There were no differences in AgRP and NPY fibre density in the PVN after the leptin antagonist (Fig. 5G and H), together suggesting that neonatal hyperleptinaemia is not solely responsible for long-term weight gain in the neonatally overfed.

\section{Discussion}

Leptin, critically involved in the hypothalamic regulation of weight gain and energy balance (Friedman \& Halaas 1998, Ahima \& Hileman 2000), has a distinct neurotrophic role during the early developmental period, stimulating the establishment of hypothalamic neuronal projections that regulate feeding and metabolism (Bouret et al. 2004b, Bouret \& Simerly 2007) without affecting food intake at this age (Mistry et al. 1999, Proulx et al. 2002). Here, we show that neonatal overfeeding leads to a long-term increase in circulating leptin, an overweight phenotype and neonatal hypothalamic leptin resistance. However, we also show novel and encouraging evidence that the neonatal overfeeding-induced early increase in ARC AgRP and NPY fibre density is reversed by adulthood so that neonatally overfed adults even have reduced NPY fibre density in the ARC compared with controls. This profile is associated with an adult normalisation of the resistance to exogenous leptin signalling that was evident in the neonatally overfed neonates. Interestingly, a short-term reduction in leptin activity by early life administration of leptin antagonist, timed to suppress any exacerbation or premature activation of the leptin surge, does not ameliorate increased body weight or leptin levels in the neonatally overfed, although it reduces hypothalamic AgRP immunoreactivity in both control and neonatally overfed rats. This finding is with a dose of antagonist that successfully restored circulating leptin and follicle maturation in neonatally overfed females (Sominsky et al. 2016b). Our data therefore indicate that neonatal overfeeding can acutely alter leptin, leptin signalling and 
A

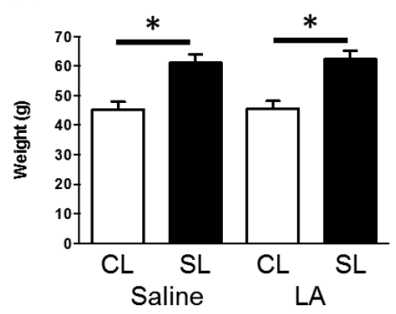

$E-A R C$ AgRP

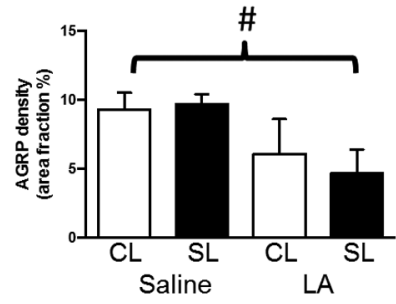

B

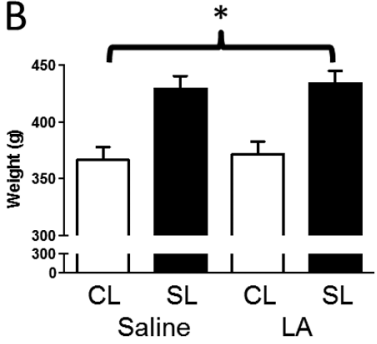

F - ARC NPY

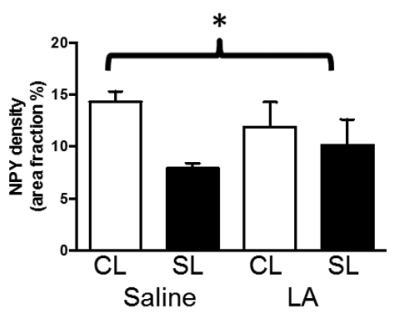

C

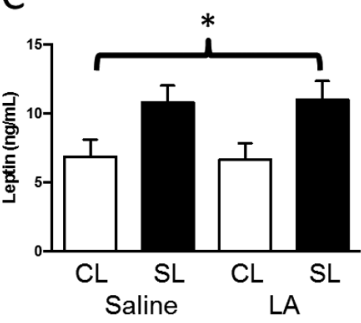

G - PVN AgRP

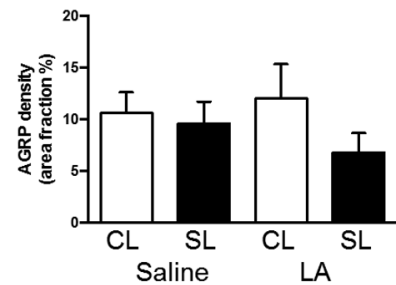

D - ARC POMC

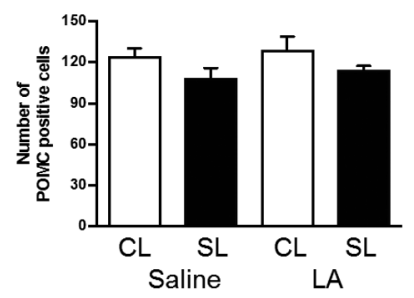

H - PVN NPY

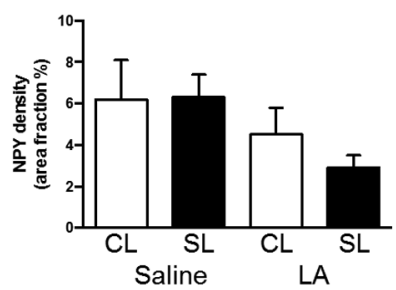

Figure 5

Long-term effects of neonatal leptin antagonist on neonatal overfeeding-induced changes in the leptin system. (A) Postnatal day (P21) and (B) adult (P56) weights in CL and SL rats given leptin antagonist or vehicle as neonates. (C) Adult plasma leptin concentrations. (D) Pro-opiomelanocortin (POMC) in the arcuate nucleus (ARC). (E) Agouti-related peptide (AgRP) in the ARC. (F) Neuropeptide Y (NPY) labelling in the ARC. (G) AgRP in the paraventricular nucleus of the hypothalamus (PVN). (H) NPY labelling in the PVN. Data are mean + S.E.M. *,\#P<0.05. A: * indicates post hoc effects. Parentheses and * in B, C and F indicate significant main effect of litter size, but no post hoc group differences. Parenthesis and \# in E indicate significant main effect of leptin antagonist, but no post hoc group differences.

hypothalamic AgRP/NPY fibre density and has significant long-term effects on weight gain and circulating leptin. However, the effects on hypothalamic satiety circuitry are unlikely to be directly due to neonatal hyperleptinaemia and are somewhat mitigated or compensated for in adults.

Despite sustained hyperleptinaemia in our neonatally overfed, we found no acute or long-term effects of neonatal overfeeding on POMC immunoreactivity, at least not in the number of cells expressing POMC. We have also found no differences in the expression of the POMC gene in the hypothalamus in neonatally overfed animals in our previous study (Sominsky et al. 2016a). These findings are similar to those reported by Plagemann and colleagues (Plagemann et al. 2009), showing no differences in hypothalamic POMC gene and protein expression, despite hyperleptinaemia in the neonatally overfed that is normally expected to lead to an increase in POMC expression (Elias et al. 1999). Those data in Plagemann's study have been found to be inversely correlated to POMC promoter methylation that is significantly increased in the neonatally overfed, so that when POMC expression is calculated per unit of leptin, an increase in methylation is inversely correlated to leptin-related POMC expression. Together, our data and those of Plagemann's group indicate that the changes in POMC promoter methylation seen by Plagemann and colleagues (Plagemann et al. 2009) may reflect an altered capacity of the system to respond to different energy balance conditions, and may indicate a propensity to suppressed expression of POMC in response to anorexigenic stimuli, but are unlikely to be directly reflected in gene transcription and protein expression.

A significant increase in circulating leptin occurs during the first two weeks of life in rodents (Ahima et al. 1998). In the present study, we demonstrate that in the neonatally overfed pups, this leptin surge is markedly exacerbated, with a fourfold increase in leptin levels compared to controls as early as P14. Given leptin's role in stimulating the growth of hypothalamic connections between the ARC and other regions of the hypothalamus, we would have expected excess leptin to be reflected in an increased density of AgRP/NPY fibres within the ARC and PVN in our neonatally overfed rats as neonates (Bouret et al. 2004b, Bouret \& Simerly 2007). Indeed, we saw an increase in AgRP and NPY density in the ARC, and a decrease in PVN NPY. NPY and AgRP are highly co-localised in the ARC with up to 99\% of ARC NPY neurons also containing AgRP (Hahn et al. 1998).

Previous studies have reported neonatal overfeeding to increase ARC NPY content (Lopez et al. 2005) and the percentage of ARC NPY neurons per total number of neurons in juvenile rats (Plagemann et al. 1999). AgRP and NPY in the PVN are also co-localised, but the

Published by Bioscientifica Ltd. 
PVN also contains a portion of NPY-positive fibres that do not contain AgRP and are not derived from the ARC (Sawchenko et al. 1985, Broberger et al. 1998, Cowley et al . 1999), potentially contributing to the stability of the AgRP density in this region in neonatally overfed rats. Interestingly, others have seen a dissociation between the AgRP and NPY responses to some stimuli (Kas et al. 2005).

In any case, the role of AgRP/NPY circuitry is to stimulate food intake, with leptin suppressing feeding by inhibiting these cells (Myers et al. 2008). One would therefore expect that increases in NPY in the ARC would lead to a strong increase in food intake. Since overweight and obesity are known to be associated with, and exacerbated by, central leptin resistance, we were interested to examine whether this occurs in the neonatally overfed and if their response to leptin is impaired. At P12, while neonatal overfeeding did not induce significant changes in the hypothalamic expression of the leptin receptor gene, the neonatally overfed ARC and VMH neurons responded less robustly to leptin. Endogenous leptin has been previously shown to mediate pSTAT3 immunoreactivity in the ARC (Faouzi et al. 2007), and the groups had similar numbers of ARC pSTAT3-positive cells under basal conditions. These findings suggest the neonatally overfed may be resistant to their excess endogenous leptin (Faouzi et al. 2007). They are also unable to respond to exogenous leptin, indicating an inability at this age to appropriately register circulating nutritional information.

Consistent with our and other groups' previous findings (Schmidt et al. 2001, Lopez et al. 2007, Stefanidis \& Spencer 2012), the elevated levels of leptin in the neonatally overfed are sustained into adulthood. This hyperleptinaemia is accompanied by, or a consequence of, an increase in adiposity, such that despite being fed a normal chow diet after weaning and eating similar amounts of it to controls (Stefanidis \& Spencer 2012), neonatally overfed rats continue to be overweight and have an increased inguinal and retroperitoneal fat mass (Stefanidis \& Spencer 2012).

Despite persistent overweight and hyperleptinaemia in the neonatally overfed, the hypothalamic responsivity to exogenous leptin was restored in adulthood, with no differences between the groups in leptin-induced pSTAT3 expression or anorexia. Persistent leptin resistance has been seen in mice after neonatal overfeeding (Glavas et al. 2010), and ARC neurons from neonatally overfed rats can maintain leptin resistance when assessed using single-unit recordings in slice preparations (Davidowa \& Plagemann 2000). However, our in vivo findings in rats are supported by previous work by Lopez and colleagues indicating that the central leptin resistance seen in neonatally overfed rats resolves in adulthood despite persistent hyperleptinaemia and significantly increased body weight (Lopez et al. 2007). This group also detected no hyperphagia and no differences in the expression of several isoforms of the leptin receptor, including its long isoform $(\mathrm{ObRb})$, the isoform assessed in our study. In accordance with this restoration of leptin sensitivity in adulthood, the NPY fibre density in the ARC was decreased in the neonatally overfed adults, and PVN density was normal. Therefore, although hypothalamic connectivity is disrupted early in life by neonatal overfeeding, there may be a compensatory development of NPY projections as the animal matures. In this regard, previous studies have shown that NPY and AgRP are particularly able to adapt to the effects of overfeeding in genetic models of impaired leptin signalling (Bouret et al. 2012), neonatal overfeeding (Lopez et al. 2007) and diet-induced obesity (Ziotopoulou et al. 2000), with a compensatory response to conditions of positive energy balance.

Given the established importance of the leptin surge in stimulating hypothalamic connectivity and our current findings that the surge, leptin signalling and this hypothalamic connectivity are disrupted by neonatal overfeeding, we hypothesised that a short-term reduction in the availability of leptin could restore some of the effects of neonatal overfeeding. While we found no effects of neonatal leptin antagonist treatment on body weight or adult leptin levels in the neonatally overfed, the antagonist reduced AgRP density in both control and neonatally overfed adult rats.

We should note that we administered the leptin antagonist from P4 to P7 in these rats and a longer or different timing of application may have different outcomes. The postnatal leptin surge that drives hypothalamic maturation begins at $\mathrm{P} 4$ and peaks at $\mathrm{P} 7-10$ in rats (Delahaye et al. 2008). Our neonatally overfed rats are overweight and hyperleptinemic around as early as P7 (Clarke et al. 2012, Stefanidis \& Spencer 2012, Sominsky et al. 2016b), indicating that an exacerbated and potentially premature leptin surge occurs in these animals. Our intention was therefore to limit the availability of leptin in the overfed pups at the beginning of the leptin surge. Previous studies using the leptin antagonist have shown that daily administration of the antagonist between $\mathrm{P} 2$ and $\mathrm{P} 13$ at $7.5 \mathrm{mg} / \mathrm{kg}$ in rat pups leads to substantial negative effects, including leptin resistance and increased susceptibility to diet-induced obesity at 4-5 months of age http://joe.endocrinology-journals.org DOI: 10.1530/JOE-16-0631
๑ 2017 Society for Endocrinology Printed in Great Britain
Published by Bioscientifica Ltd 
(Attig et al. 2008, Benoit et al. 2013). It also modifies the hypothalamic miRNA expression pattern in adulthood, and impairs maturation of pancreas, kidney, thymus and ovary (Attig et al. 2008, 2011, Benoit et al. 2013). We therefore chose to use a short time frame of exposure to the antagonist that would attenuate this early surge without directly affecting leptin activity in the longer term. We thus administered the leptin antagonist between P4 and P7 only. These protocols followed recent studies by Mela and colleagues (Mela et al. 2015, 2016) where the same dose of antagonist $(5 \mathrm{mg} / \mathrm{kg})$ and a similar limited timing (P5-P9) were used to investigate early leptin's effects on reproductive parameters pre- and post-puberty. We have also used the same drug regimen in neonatally overfed female rats in our recently published study (Sominsky et al. 2016b). In this study, we found that this short-term postnatal administration of leptin antagonist rescued the decline in the primordial follicle pool caused by neonatal overfeeding and abolished the differences in circulating adult leptin and gonadotrophins between the neonatally overfed and control female rats. In the present study, we were interested to investigate whether we could reverse the hyperleptinaemia as we saw in females and the hypothalamic changes in male rats.

Together, our data suggest that an exacerbated leptin surge and a concomitant increase in body weight induced by neonatal overfeeding are associated with an acute effect on the developing hypothalamus, leading to alterations in the establishment of the central mechanisms that regulate metabolism. It appears, however, that most of this altered functionality is restored in adulthood. In this regard, we have recently shown that neonatal overfeeding does not increase susceptibility to the negative metabolic effects of high-fat diet commenced in adulthood, at least not after short periods of dietary exposure, and does not affect glucose metabolism (Cai et al. 2015). We have also recently demonstrated that neonatal overfeeding induces acute changes in the brain's sensitivity to ghrelin that are not maintained into adulthood (Sominsky et al. 2016a). For future studies, it will be interesting to examine changes in other peripherally acting hormones that communicate with central regulators of energy balance, such as insulin and GLP-1. Nevertheless, these findings are potentially encouraging for the neonatally overfed, suggesting that despite major changes early on to the central pathways that regulate metabolism, the brain is able to significantly compensate to restore normal metabolic processes as the animal matures.

\section{Declaration of interest}

The authors declare that there is no conflict of interest that could be perceived as prejudicing the impartiality of the research reported.

\section{Funding}

This work was supported by a Discovery Project Grant from the Australian Research Council (ARC) to S J S (DP130100508). S J S is an ARC Future Fellow (FT110100084) and an RMIT University VC Senior Research Fellow.

\section{References}

Ahima RS \& Hileman SM 2000 Postnatal regulation of hypothalamic neuropeptide expression by leptin: implications for energy balance and body weight regulation. Regulatory Peptides 92 1-7. (doi:10.1016/ S0167-0115(00)00142-7)

Ahima RS, Prabakaran D \& Flier JS 1998 Postnatal leptin surge and regulation of circadian rhythm of leptin by feeding. Implications for energy homeostasis and neuroendocrine function. Journal of Clinical Investigation 101 1020-1027. (doi:10.1172/JCI1176)

Attig L, Solomon G, Ferezou J, Abdennebi-Najar L, Taouis M, Gertler A \& Djiane J 2008 Early postnatal leptin blockage leads to a long-term leptin resistance and susceptibility to diet-induced obesity in rats. International Journal of Obesity 32 1153-1160. (doi:10.1038/ijo.2008.39)

Attig L, Larcher T, Gertler A, Abdennebi-Najar L \& Djiane J 2011 Postnatal leptin is necessary for maturation of numerous organs in newborn rats. Organogenesis 7 88-94. (doi:10.4161/org.7.2.14871)

Benoit C, Ould-Hamouda H, Crepin D, Gertler A, Amar L \& Taouis M 2013 Early leptin blockade predisposes fat-fed rats to overweight and modifies hypothalamic microRNAs. Journal of Endocrinology 218 35-47. (doi:10.1530/JOE-12-0561)

Berman Y, Mzhavia N, Polonskaia A \& Devi LA 2001 Impaired prohormone convertases in Cpe(fat)/Cpe(fat) mice. Journal of Biological Chemistry 276 1466-1473. (doi:10.1074/jbc.M008499200)

Betley JN, Xu S, Cao ZF, Gong R, Magnus CJ, Yu Y \& Sternson SM 2015 Neurons for hunger and thirst transmit a negative-valence teaching signal. Nature 521 180-185. (doi:10.1038/nature14416)

Boney CM, Verma A, Tucker R \& Vohr BR 2005 Metabolic syndrome in childhood: association with birth weight, maternal obesity, and gestational diabetes mellitus. Pediatrics 115 e290-e296. (doi:10.1542/ peds.2004-1808)

Bouret SG 2009 Early life origins of obesity: role of hypothalamic programming. Journal of Pediatric Gastroenterology and Nutrition 48 (Supplement 1) S31-S38. (doi:10.1097/MPG.0b013e3181977375)

Bouret SG \& Simerly RB 2006 Developmental programming of hypothalamic feeding circuits. Clinical Genetics 70 295-301. (doi:10.1111/j.1399-0004.2006.00684.x)

Bouret SG \& Simerly RB 2007 Development of leptin-sensitive circuits. Journal of Neuroendocrinology 19 575-582. (doi:10.1111/j.13652826.2007.01563.x)

Bouret SG, Draper SJ \& Simerly RB 2004a Formation of projection pathways from the arcuate nucleus of the hypothalamus to hypothalamic regions implicated in the neural control of feeding behavior in mice. Journal of Neuroscience 24 2797-2805. (doi:10.1523/ JNEUROSCI.5369-03.2004)

Bouret SG, Draper SJ \& Simerly RB 2004b Trophic action of leptin on hypothalamic neurons that regulate feeding. Science 304 108-110. (doi:10.1126/science.1095004)

Bouret SG, Bates SH, Chen S, Myers MG Jr \& Simerly RB 2012 Distinct roles for specific leptin receptor signals in the development of
๑ 2017 Society for Endocrinology Printed in Great Britain 
hypothalamic feeding circuits. Journal of Neuroscience 32 1244-1252. (doi:10.1523/JNEUROSCI.2277-11.2012)

Broberger C, Johansen J, Johansson C, Schalling M \& Hokfelt T 1998 The neuropeptide $\mathrm{Y} /$ agouti gene-related protein (AGRP) brain circuitry in normal, anorectic, and monosodium glutamate-treated mice. PNAS 95 15043-15048. (doi:10.1073/pnas.95.25.15043)

Cai G, Dinan T, Barwood JM, De Luca SN, Soch A, Ziko I, Chan SMH, Zheng XY, Li S, Molero J, et al. 2015 Neonatal overfeeding attenuates acute central pro-inflammatory effects of short-term high fat diet. Frontiers in Neuroscience 8 1-13.

Cao Y, Nakata M, Okamoto S, Takano E, Yada T, Minokoshi Y, Hirata Y, Nakajima K, Iskandar K, Hayashi Y, et al. 2011 PDK1-Foxo1 in agouti-related peptide neurons regulates energy homeostasis by modulating food intake and energy expenditure. PLOS ONE 6 e18324. (doi:10.1371/journal.pone.0018324)

Cheng CY, Chu JY \& Chow BK 2011 Central and peripheral administration of secretin inhibits food intake in mice through the activation of the melanocortin system. Neuropsychopharmacology $\mathbf{3 6}$ 459-471. (doi:10.1038/npp.2010.178)

Cheunsuang O \& Morris R 2005 Astrocytes in the arcuate nucleus and median eminence that take up a fluorescent dye from the circulation express leptin receptors and neuropeptide Y Y1 receptors. Glia 52 228-233. (doi:10.1002/glia.20239)

Clarke MA, Stefanidis A \& Spencer SJ 2012 Postnatal overfeeding leads to obesity and exacerbated febrile responses to lipopolysaccharide throughout life. Journal of Neuroendocrinology 24 511-524. (doi:10.1111/j.1365-2826.2011.02269.x)

Collden G, Balland E, Parkash J, Caron E, Langlet F, Prevot V \& Bouret SG 2015 Neonatal overnutrition causes early alterations in the central response to peripheral ghrelin. Molecular Metabolism 4 15-24. (doi:10.1016/j.molmet.2014.10.003)

Cottrell EC, Cripps RL, Duncan JS, Barrett P, Mercer JG, Herwig A \& Ozanne SE 2009 Developmental changes in hypothalamic leptin receptor: relationship with the postnatal leptin surge and energy balance neuropeptides in the postnatal rat. American Journal of Physiology: Regulatory, Integrative and Comparative Physiology 296 R631-R639.

Cowley MA, Pronchuk N, Fan W, Dinulescu DM, Colmers WF \& Cone RD 1999 Integration of NPY, AGRP, and melanocortin signals in the hypothalamic paraventricular nucleus: evidence of a cellular basis for the adipostat. Neuron 24 155-163. (doi:10.1016/S08966273(00)80829-6)

Cowley MA, Smart JL, Rubinstein M, Cerdan MG, Diano S, Horvath TL, Cone RD \& Low MJ 2001 Leptin activates anorexigenic POMC neurons through a neural network in the arcuate nucleus. Nature $\mathbf{4 1 1}$ 480-484.

Davidowa H \& Plagemann A 2000 Decreased inhibition by leptin of hypothalamic arcuate neurons in neonatally overfed young rats. Neuroreport 11 2795-2798. (doi:10.1097/00001756-20000821000037)

DeBoer MD, Scarlett JM, Levasseur PR, Grant WF \& Marks DL 2009 Administration of IL-1beta to the 4 th ventricle causes anorexia that is blocked by agouti-related peptide and that coincides with activation of tyrosine-hydroxylase neurons in the nucleus of the solitary tract. Peptides 30 210-218. (doi:10.1016/j.peptides.2008.10.019)

Delahaye F, Breton C, Risold PY, Enache M, Dutriez-Casteloot I, Laborie C, Lesage J \& Vieau D 2008 Maternal perinatal undernutrition drastically reduces postnatal leptin surge and affects the development of arcuate nucleus proopiomelanocortin neurons in neonatal male rat pups. Endocrinology 149 470-475. (doi:10.1210/en.2007-1263)

Desai M, Gayle D, Han G \& Ross MG 2007 Programmed hyperphagia due to reduced anorexigenic mechanisms in intrauterine growth-restricted offspring. Reproductive Sciences 14 329-337. (doi:10.1177/1933719107303983)

Elias CF, Aschkenasi C, Lee C, Kelly J, Ahima RS, Bjorbaek C, Flier JS, Saper CB \& Elmquist JK 1999 Leptin differentially regulates NPY and
POMC neurons projecting to the lateral hypothalamic area. Neuron 23 775-786. (doi:10.1016/S0896-6273(01)80035-0)

Evans JM, Bey V, Burkey AR \& Commons KG 2007 Organization of endogenous opioids in the rostral agranular insular cortex of the rat. Journal of Comparative Neurology $\mathbf{5 0 0} 530-541$. (doi:10.1002/ cne.21197)

Faouzi M, Leshan R, Bjornholm M, Hennessey T, Jones J \& Munzberg H 2007 Differential accessibility of circulating leptin to individual hypothalamic sites. Endocrinology 148 5414-5423. (doi:10.1210/ en.2007-0655)

Friedman JM \& Halaas JL 1998 Leptin and the regulation of body weight in mammals. Nature 395 763-770. (doi:10.1038/27376)

Frontini A, Bertolotti P, Tonello C, Valerio A, Nisoli E, Cinti S \& Giordano A 2008 Leptin-dependent STAT3 phosphorylation in postnatal mouse hypothalamus. Brain Research 1215 105-115. (doi:10.1016/j. brainres.2008.03.078)

Garcia AP, Palou M, Priego T, Sanchez J, Palou A \& Pico C 2010 Moderate caloric restriction during gestation results in lower arcuate nucleus NPY- and alphaMSH-neurons and impairs hypothalamic response to fed/fasting conditions in weaned rats. Diabetes, Obesity and Metabolism 12 403-413. (doi:10.1111/j.1463-1326.2009.01174.x)

Garcia AP, Palou M, Sanchez J, Priego T, Palou A \& Pico C 2011 Moderate caloric restriction during gestation in rats alters adipose tissue sympathetic innervation and later adiposity in offspring. PLOS ONE 6 e17313. (doi:10.1371/journal.pone.0017313)

Garfield AS, Li C, Madara JC, Shah BP, Webber E, Steger JS, Campbell JN, Gavrilova O, Lee CE, Olson DP, et al. 2015 A neural basis for melanocortin-4 receptor-regulated appetite. Nature Neuroscience 18 863-871. (doi:10.1038/nn.4011)

Glavas MM, Kirigiti MA, Xiao XQ, Enriori PJ, Fisher SK, Evans AE, Grayson BE, Cowley MA, Smith MS \& Grove KL 2010 Early overnutrition results in early-onset arcuate leptin resistance and increased sensitivity to high-fat diet. Endocrinology 151 1598-1610. (doi:10.1210/en.2009-1295)

Gotoh K, Liu M, Benoit SC, Clegg DJ, Davidson WS, D'Alessio D, Seeley RJ, Tso P \& Woods SC 2006 Apolipoprotein A-IV interacts synergistically with melanocortins to reduce food intake. American Journal of Physiology: Regulatory, Integrative and Comparative Physiology 290 R202-R207.

Hahn TM, Breininger JF, Baskin DG \& Schwartz MW 1998 Coexpression of Agrp and NPY in fasting-activated hypothalamic neurons. Nature Neuroscience 1 271-272. (doi:10.1038/1082)

Kas MJ, Bruijnzeel AW, Haanstra JR, Wiegant VM \& Adan RA 2005 Differential regulation of agouti-related protein and neuropeptide $\mathrm{Y}$ in hypothalamic neurons following a stressful event. Journal of Molecular Endocrinology 35 159-164. (doi:10.1677/jme.1.01819)

Kenny R, Dinan T, Cai G \& Spencer SJ 2014 Effects of mild calorie restriction on anxiety and hypothalamic-pituitary-adrenal axis responses to stress in the male rat. Physiological Reports 2 e00265.

Kim ER, Lew PS, Spirkina A \& Mizuno TM 2016 Xenin-induced feeding suppression is not mediated through the activation of central extracellular signal-regulated kinase signaling in mice. Behavioural Brain Research 312 118-126. (doi:10.1016/j.bbr.2016.06.026)

Kobelt P, Wisser AS, Stengel A, Goebel M, Inhoff T, Noetzel S, Veh RW, Bannert N, van der Voort I, Wiedenmann B, et al. 2008 Peripheral injection of ghrelin induces Fos expression in the dorsomedial hypothalamic nucleus in rats. Brain Research 1204 77-86. (doi:10.1016/j.brainres.2008.01.054)

Konieczna J, Garcia AP, Sanchez J, Palou M, Palou A \& Pico C 2013 Oral leptin treatment in suckling rats ameliorates detrimental effects in hypothalamic structure and function caused by maternal caloric restriction during gestation. PLOS ONE 8 e81906. (doi:10.1371/ journal.pone.0081906)

Li AJ, Wiater MF, Oostrom MT, Smith BR, Wang Q, Dinh TT, Roberts BL, Jansen HT \& Ritter S 2012 Leptin-sensitive neurons in the arcuate nuclei contribute to endogenous feeding rhythms. American Journal 
of Physiology: Regulatory, Integrative and Comparative Physiology 302 R1313-R1326.

Lopez M, Seoane LM, Tovar S, Garcia MC, Nogueiras R, Dieguez C \& Senaris RM 2005 A possible role of neuropeptide Y, agouti-related protein and leptin receptor isoforms in hypothalamic programming by perinatal feeding in the rat. Diabetologia 48 140-148. (doi:10.1007/ s00125-004-1596-z)

Lopez M, Tovar S, Vazquez MJ, Nogueiras R, Seoane LM, Garcia M, Senaris RM \& Dieguez C 2007 Perinatal overfeeding in rats results in increased levels of plasma leptin but unchanged cerebrospinal leptin in adulthood. International Journal of Obesity 31 371-377. (doi:10.1038/sj.ijo.0803425)

Mao S, Li X, Wang J, Ding X, Zhang C \& Li L 2016 miR-17-92 facilitates neuronal differentiation of transplanted neural stem/precursor cells under neuroinflammatory conditions. Journal of Neuroinflammation 13 208. (doi:10.1186/s12974-016-0685-5)

McCance RA 1962 Food, growth, and time. Lancet 2 671-676. (doi:10.1016/S0140-6736(62)90499-3)

McGuckin CP, Jurga M, Miller AM, Sarnowska A, Wiedner M, Boyle NT, Lynch MA, Jablonska A, Drela K, Lukomska B, et al. 2013 Ischemic brain injury: a consortium analysis of key factors involved in mesenchymal stem cell-mediated inflammatory reduction. Archives of Biochemistry and Biophysics 534 88-97. (doi:10.1016/j. abb.2013.02.005)

Mela V, Diaz F, Lopez-Rodriguez AB, Vazquez MJ, Gertler A, Argente J, Tena-Sempere M, Viveros MP \& Chowen JA 2015 Blockage of the neonatal leptin surge affects the gene expression of growth factors, glial proteins, and neuropeptides involved in the control of metabolism and reproduction in peripubertal male and female rats. Endocrinology 156 2571-2581.

Mela V, Jimenez S, Freire-Regatillo A, Barrios V, Marco EM, LopezRodriguez AB, Argente J, Viveros MP \& Chowen JA 2016 Blockage of neonatal leptin signaling induces changes in the hypothalamus associated with delayed pubertal onset and modifications in neuropeptide expression during adulthood in male rats. Peptides $\mathbf{8 6}$ 63-71. (doi:10.1016/j.peptides.2016.10.003)

Mistry AM, Swick A \& Romsos DR 1999 Leptin alters metabolic rates before acquisition of its anorectic effect in developing neonatal mice. American Journal of Physiology 277 R742-R747.

Myers MG, Cowley MA \& Munzberg H 2008 Mechanisms of leptin action and leptin resistance. Annual Review of Physiology 70 537-556. (doi:10.1146/annurev.physiol.70.113006.100707)

Oliver P, Pico C, De Matteis R, Cinti S \& Palou A 2002 Perinatal expression of leptin in rat stomach. Developmental Dynamics 223 148-154. (doi:10.1002/dvdy.1233)

Pandit R, Omrani A, Luijendijk MC, de Vrind VA, Van Rozen AJ, Ophuis RJ, Garner K, Kallo I, Ghanem A, Liposits Z, et al. 2016 Melanocortin 3 receptor signaling in midbrain dopamine neurons increases the motivation for food reward. Neuropsychopharmacology 41 2241-2251. (doi:10.1038/npp.2016.19)

Paxinos G \& Watson C 2009 The Rat Brain in Stereotaxic Coordinates. San Diego, CA, USA: Academic Press, Elsevier.

Pekala D, Blasiak T, Raastad M \& Lewandowski MH 2011 The influence of orexins on the firing rate and pattern of rat intergeniculate leaflet neurons - electrophysiological and immunohistological studies. European Journal of Neuroscience 34 1406-1418. (doi:10.1111/j.14609568.2011.07868.x)

Plagemann A, Harder T, Rake A, Waas T, Melchior K, Ziska T, Rohde W \& Dorner G 1999 Observations on the orexigenic hypothalamic neuropeptide Y-system in neonatally overfed weanling rats. Journal of Neuroendocrinology 11 541-546. (doi:10.1046/j.13652826.1999.00357.x)

Plagemann A, Harder T, Brunn M, Harder A, Roepke K, Wittrock-Staar M, Ziska T, Schellong K, Rodekamp E, Melchior K, et al. 2009 Hypothalamic proopiomelanocortin promoter methylation becomes altered by early overfeeding: an epigenetic model of obesity and the metabolic syndrome. Journal of Physiology 587 4963-4976. (doi:10.1113/jphysiol.2009.176156)

Proulx K, Richard D \& Walker CD 2002 Leptin regulates appetite-related neuropeptides in the hypothalamus of developing rats without affecting food intake. Endocrinology 143 4683-4692. (doi:10.1210/ en.2002-220593)

Reyes BA, Glaser JD, Magtoto R \& Van Bockstaele EJ 2006 Proopiomelanocortin colocalizes with corticotropin-releasing factor in axon terminals of the noradrenergic nucleus locus coeruleus. European Journal of Neuroscience 23 2067-2077. (doi:10.1111/j.14609568.2006.04744.x)

Sachot C, Rummel C, Bristow AF \& Luheshi GN 2007 The role of the vagus nerve in mediating the long-term anorectic effects of leptin. Journal of Neuroendocrinology 19 250-261. (doi:10.1111/j.13652826.2006.01528.x)

Sawchenko PE, Swanson LW, Grzanna R, Howe PR, Bloom SR \& Polak JM 1985 Colocalization of neuropeptide Y immunoreactivity in brainstem catecholaminergic neurons that project to the paraventricular nucleus of the hypothalamus. Journal of Comparative Neurology 241 138-153. (doi:10.1002/cne.902410203)

Schmidt I, Fritz A, Scholch C, Schneider D, Simon E \& Plagemann A 2001 The effect of leptin treatment on the development of obesity in overfed suckling Wistar rats. International Journal of Obesity and Related Metabolic Disorders 25 1168-1174. (doi:10.1038/sj.ijo.0801669)

Schmittgen TD \& Livak KJ 2008 Analyzing real-time PCR data by the comparative C(T) method. Nature Protocols 3 1101-1108. (doi:10.1038/nprot.2008.73)

Shibata M, Banno R, Sugiyama M, Tominaga T, Onoue T, Tsunekawa T, Azuma Y, Hagiwara D, Lu W, Ito Y, et al. 2016 AgRP neuronspecific deletion of glucocorticoid receptor leads to increased energy expenditure and decreased body weight in female mice on a high-fat diet. Endocrinology 157 1457-1466. (doi:10.1210/en.2015-1430)

Shpilman M, Niv-Spector L, Katz M, Varol C, Solomon G, Ayalon-Soffer M, Boder E, Halpern Z, Elinav E \& Gertler A 2011 Development and characterization of high affinity leptins and leptin antagonists. Journal of Biological Chemistry 286 4429-4442. (doi:10.1074/jbc. M110.196402)

Singru PS, Wittmann G, Farkas E, Zseli G, Fekete C \& Lechan RM 2012 Refeeding-activated glutamatergic neurons in the hypothalamic paraventricular nucleus (PVN) mediate effects of melanocortin signaling in the nucleus tractus solitarius (NTS). Endocrinology 153 3804-3814. (doi:10.1210/en.2012-1235)

Smith JT \& Spencer SJ 2012 Preweaning over- and underfeeding alters onset of puberty in the rat without affecting kisspeptin. Biology of Reproduction 86 145; 141-148.

Sominsky L, Ziko I, Nguyen TX, Andrews ZB \& Spencer SJ 2016a Early life disruption to the ghrelin system with over-eating is resolved in adulthood in male rats. Neuropharmacology 113 21-30. (doi:10.1016/j. neuropharm.2016.09.023)

Sominsky L, Ziko I, Soch A, Smith JT \& Spencer SJ 2016b Neonatal overfeeding induces early decline of the ovarian reserve: implications for the role of leptin. Molecular and Cellular Endocrinology 431 24-35. (doi:10.1016/j.mce.2016.05.001)

Spencer SJ \& Tilbrook A 2009 Neonatal overfeeding alters adult anxiety and stress responsiveness. Psychoneuroendocrinology 34 1133-1143. (doi:10.1016/j.psyneuen.2009.02.013)

Stefanidis A \& Spencer SJ 2012 Effects of neonatal overfeeding on juvenile and adult feeding and energy expenditure in the rat. PLoS ONE 7 e52130. (doi:10.1371/journal.pone.0052130)

Tavares E, Maldonado R \& Minano FJ 2013 Aminoprocalcitonin-mediated suppression of feeding involves the hypothalamic melanocortin system. American Journal of Physiology: Endocrinology and Metabolism 304 E1251-E1262.

Whitaker RC 2004 Predicting preschooler obesity at birth: the role of maternal obesity in early pregnancy. Pediatrics 114 e29-e36. (doi:10.1542/peds.114.1.e29) 
Wittmann G, Hrabovszky E \& Lechan RM 2013 Distinct glutamatergic and GABAergic subsets of hypothalamic pro-opiomelanocortin neurons revealed by in situ hybridization in male rats and mice. Journal of Comparative Neurology 521 3287-3302. (doi:10.1002/ cne.23350)

Zhan C, Zhou J, Feng Q, Zhang JE, Lin S, Bao J, Wu P \& Luo M 2013 Acute and long-term suppression of feeding behavior by POMC neurons in the brainstem and hypothalamus, respectively. Journal of Neuroscience 33 3624-3632. (doi:10.1523/ JNEUROSCI.2742-12.2013)

Ziotopoulou M, Mantzoros CS, Hileman SM \& Flier JS 2000 Differential expression of hypothalamic neuropeptides in the early phase of dietinduced obesity in mice. American Journal of Physiology: Endocrinology and Metabolism 279 E838-E845.

Received in final form 26 April 2017

Accepted 28 April 2017

Accepted Preprint published online 28 April 2017
Published by Bioscientifica Ltd. 